\title{
Notas Científicas \\ Variação no teor de lipídios em grãos de variedades de Coffea canephora
}

\author{
Adriano Tosoni da Eira Aguiar(1), Terezinha de Jesus Garcia Salva ${ }^{(1)}$, Luiz Carlos Fazuoli(1) e José Laércio Favarin(2) \\ (1)Instituto Agronômico, Centro de Análise e Pesquisa Tecnológica do Agronegócio do Café Alcides Carvalho, Caixa Postal 28, CEP 13001-970 \\ Campinas, SP. E-mail: aguiar@iac.sp.gov.br, tsalva@iac.sp.gov.br, fazuoli@iac.sp.gov.br (2)Escola Superior de Agricultura Luiz de Queiroz, \\ Dep. de Produção Vegetal, Av. Pádua Dias, no 11, Caixa Postal 9, CEP 13418-900 Piracicaba, SP. E-mail: jlfavari@esalq.usp.br
}

\begin{abstract}
Resumo - O objetivo deste trabalho foi estudar a variação do teor de lipídios em grãos de diferentes variedades de Coffea canephora Pierre, do Banco de Germoplasma de Café, do Instituto Agronômico, Campinas, SP, Brasil. Foram analisadas sementes de 47 plantas pertencentes às variedades Robusta (3), Kouilou ou Conilon 66 (13), Apoatã (12), Guarini (8), Laurentii (7) e Bukobensis (4). A quantidade de matéria graxa foi determinada após extração com éter de petróleo. Os resultados revelaram diferença entre o teor médio de lipídios das variedades Kouilou (7,33\%) e Robusta (10,91\%). Foram constatadas diferenças também dentro das plantas das seis variedades, com amplitudes de 15,57\% a 21,63\% em Apoatã e Laurentii, respectivamente.
\end{abstract}

Termos para indexação: café robusta, germoplasma, componente químico.

\section{Variation of seed lipid content among Coffea canephora varieties}

\begin{abstract}
The objective of this work was to investigate the variation of lipid content in beans from different varieties of Coffea canephora Pierre specie, from the Coffee Germplasm Bank, of Instituto Agronômico, Campinas, SP, Brazil. Samples of green coffee from 47 plants were analysed: Robusta (3), Kouilou or Conilon 66 (13), Apoatã (12), Guarini (8), Laurentii (7) and Bukobensis (4). Oil content was determined after a petroleum ether extraction. Results showed difference among the average lipid content in Kouilou, at 7.33\% and Robusta, at 10.91\%. Differences were also observed within plants from the six varieties ranging from $15.57 \%$ to $21.63 \%$, for Apoatã and Laurentii, respectively.
\end{abstract}

Index terms: robust coffee, germplasm, chemical component.

O cafeeiro é pertencente à família Rubiaceae e há aproximadamente 100 espécies dessa planta. Entretanto, somente Coffea arabica L. e C. canephora Pierre têm importância econômica (Berthaud \& Charrier, 1988). Aproximadamente $70 \%$ do café brasileiro provêm de variedades de C. arabica L. e $30 \%$ de C. canephora Pierre (Agrianual, 2004). A espécie C. canephora Pierre, também denominada café robusta, foi introduzida no Brasil por volta de 1920. É uma planta diplóide, autoincompatível (Conagin \& Mendes, 1961), que se multiplica por fecundação cruzada, principalmente pela ação do vento e dos insetos. Segundo Dussert et al. (1999), C. canephora apresenta dois grupos distintos, em razão de sua região de ocorrência: grupo Guineano, que engloba plantas da Guiné, Libéria e Costa do Marfim, e grupo Congolês, que compreende plantas da região que se estende de Angola, Zaire, Congo, Gabão até Camarões.

As variedades de C. canephora Pierre revelam grande diversidade genética em relação às características agronômicas e morfológicas, que se devem à própria origem da espécie (Carvalho, 1946; Berthaud \& Charrier, 1988; Dussert et al., 1999).

Segundo Ky et al. (2001), as diferenças entre as variedades de C. canephora Pierre ocorrem também nos níveis molecular e bioquímico. Dos trabalhos disponíveis, que tratam da diversidade entre as variedades de C. canephora, pode-se citar o de Mazzafera et al. (1998), que constataram diferenças entre os teores de 
lipídios de C. canephora variedade Robusta e C. canephora variedade Kouilou, do Banco de Germoplasma do Instituto Agronômico, Campinas, SP. Diferenças também foram verificadas nos teores de cafeína, ácidos clorogênicos totais e ácidos 3-cafeoilquínico, 4,5-dicafeoilquínico e 5-feruoilquínico, de acessos de C. canephora da Guiné, Congo, República da África Central, de Camarões e Costa do Marfim (Ky et al., 2001). Os lipídios possuem um efeito benéfico na qualidade da bebida do café, pois, durante a torração, concentram-se nas áreas externas, formando na semente uma camada protetora contra eventuais perdas ocasionadas pelo processo (Pimenta, 2003).

O objetivo deste trabalho foi investigar a variabilidade do teor de lipídios, em grãos da espécie C. canephora Pierre.

Foram utilizados grãos oriundos de frutos de 47 plantas, de seis variedades botânicas de café robusta (Coffea canephora Pierre), mantidas no Banco de Germoplasma de Café do Centro de Análise e Pesquisa Tecnológica do Agronegócio do Café Alcides Carvalho, do Instituto Agronômico. Os tratos culturais foram realizados de acordo com as recomendações adotadas para a cultura (Fazuoli et al., 1998).

Frutos de cada planta foram colhidos no estádio de maturação cereja e, em seguida, foram despolpados. Depois da fermentação (degomagem), os grãos foram secados ao sol em plástico perfurado, até o teor de, aproximadamente, $11 \%$ de umidade; posteriormente, os grãos foram beneficiados e os grãos de café cru foram moídos em moinho da marca Foss-Tecator refrigerado com água, peneirados em peneira de 0,5 mm (ABNT 35, Tyler 32) e acondicionados em sacos de plástico até o momento das análises.

Para determinar o teor de umidade dos grãos, utilizaram-se aproximadamente $5 \mathrm{~g}$ de café cru moído, que foi colocado em placa de Petri e mantido em estufa a $105 \pm 1^{\circ} \mathrm{C}$ até peso constante.

Na determinação dos lipídios totais, utilizaram-se aproximadamente 5 g de café cru moído. A extração foi feita com cerca de $100 \mathrm{~mL}$ de éter de petróleo com sobrefluxo, durante 16 horas, em aparato "Butt". A pesagem do material sólido foi feita depois da secagem, durante uma noite, em temperatura ambiente, e durante 30 minutos em estufa a $105^{\circ} \mathrm{C}$. A concentração de lipídios foi calculada pela diferença entre a massa de café inicial e a desengordurada seca, durante 30 minutos, e 1 hora em estufa a $105^{\circ} \mathrm{C}$ (Mazzafera et al., 1998).

O delineamento adotado foi o hierárquico, com dados totalmente aninhados, e as plantas em cada variedade refletem o fator de aninhamento, segundo método de Pezzopane et al. (2004). Os resultados foram submetidos à análise de variância pelo programa estatístico Minitab. Por essa análise, foram obtidos o coeficiente de variação do experimento, o desvio-padrão e o intervalo de confiança da média. As médias foram comparadas pelo teste de Tukey a 5\% de probabilidade, de acordo com Banzatto \& Kronka (1995).

Foi encontrada variação significativa no teor de lipídios dos grãos, nas seis variedades estudadas (Tabela 1). Essa variabilidade encontrada entre cafeeiros de uma mesma variedade se deve, em grande parte, às diferenças genéticas existentes entre eles, pois, como são plantas alógamas e foram obtidas via sexuada (semente), essas variações eram esperadas. A mesma variação foi observada entre as variedades (Tabela 2), e isto se deve, principalmente, à origem genética da espécie (região de ocorrência muito ampla) (Dussert et al., 1999).

O coeficiente de variação, obtido a partir da análise de variância do teor de lipídios, foi de 3,43\%, o que indica boa precisão. Quanto a esse teor, as variedades podem ser divididas em três grupos: (i) variedade Robusta; (ii) variedades Apoatã, Guarini, Laurentii e Bukobensis; e (iii) variedade Kouilou 66 (Tabela 2).

Os grãos da variedade Robusta (grupo i) apresentaram os maiores teores de lipídios, com média de $10,91 \%$, e amplitude de variação de $20,11 \%$, o que concorda com resultados encontrados na literatura (Streuli, 1973). Mazzafera et al. (1998) encontraram valores pouco inferiores, em torno de 9,83\%. Como as plantas de $C$. canephora Pierre são alógamas, é possível que essas pequenas diferenças encontradas se devam, em parte, às diferenças genéticas existentes entre as sementes das plantas estudadas, principalmente por serem constituídas pelo endosperma triplóide, em que 2n cromossomos são provenientes da planta mãe e $1 \mathrm{n}$ do pai doador do grão de pólen. Trata-se de uma variedade pertencente ao grupo denominado Congolês, que possui região de ocorrência bastante ampla. Desde que

Tabela 1. Análise de variância dos valores de lipídios totais, em 47 plantas de Coffea canephora Pierre.

\begin{tabular}{lcrc}
\hline Fonte de variação & GL & QM & F \\
\hline Variedade & 5 & 19,63 & $12,92^{*}$ \\
Planta & 41 & 1,52 & $16,50^{*}$ \\
Erro & 47 & 0,09 & \\
\hline Total & 93 & & \\
\hline
\end{tabular}

*Significativo a $5 \%$ de probabilidade. 
foi introduzida no Brasil, essa variedade vem sendo muito estudada e, mediante seleções, desenvolveram-se outras variedades e clones.

Os teores de lipídios dos grãos do grupo composto por Apoatã, Bukobensis, Laurentii e Guarini (ii) ficaram entre $9,07 \%$ e $9,44 \%$. O menor e o maior valor foram observados nas variedades Laurentii e Bukobensis. Essas variedades, que ainda não foram estudadas quanto ao teor de lipídios, apresentaram valores intermediários entre Robusta e Kouilou. A variedade Apoatã, com teor médio de lipídios nos grãos igual a 9,36\%, foi lançada e distribuída aos produtores em 1987 e vem sendo muito utilizada como porta-enxerto para as variedades de C. arabica, em regiões infestadas por nematóides do gênero Meloidogyne (Fazuoli et al., 1999).

Embora as variedades Apoatã, Bukobensis, Laurentii e Guarini tenham a mesma origem e características fenotípicas semelhantes às da Robusta, as diferenças observadas nos teores de lipídios poderão ser explicadas por suas constituições genéticas, isto é, por apresentarem, em graus variáveis, grande número de locos em heterozigose (Berthaud \& Charrier, 1988).

O teor médio de lipídios totais, encontrado nos grãos da variedade Kouilou grupo (iii), 7,33\%, com amplitude de variação de $17,21 \%$, está de acordo com o obtido por Mazzafera et al. (1998), que encontraram valor médio de $8,08 \%$. Essa variedade ficou caracterizada por possuir o menor valor para a característica, com apenas 7,33\% de lipídios em suas sementes. Trata-se da variedade de C. canephora Pierre mais plantada no Brasil (Matiello, 1998), especialmente no Estado do Espírito Santo, onde corresponde a 60\% da produção total de café (Ferrão et al., 2000).

O teor de lipídios encontrado na variedade Kouilou 66 decorre de suas características genotípicas serem distintas das demais variedades analisadas. Essa variedade pertence à outra região de ocorrência, denominada grupo Guineano. Segundo Ky et al. (2001), algumas variáveis químicas, tais como cafeína e ácido

Tabela 2. Número de plantas (N) e teor médio de lipídios (L) de seis variedades de Coffea canephora Pierre.

\begin{tabular}{lrrr}
\hline Variedade & $\mathrm{N}$ & \multicolumn{1}{c}{$\mathrm{L}^{(1)}$} & $\mathrm{CV}$ \\
\hline Apoatã & 12 & $9,36 \mathrm{~b}$ & 8,44 \\
Robusta & 3 & $10,91 \mathrm{a}$ & 11,18 \\
Bukobensis & 4 & $9,44 \mathrm{~b}$ & 11,44 \\
Laurentii & 7 & $9,07 \mathrm{~b}$ & 12,13 \\
Guarini & 8 & $9,27 \mathrm{~b}$ & 8,52 \\
Kouilou 66 & 13 & $7,33 \mathrm{c}$ & 9,41 \\
\hline
\end{tabular}

(1)Médias de duas repetições, seguidas da mesma letra, não diferem entre si a $5 \%$ de probabilidade, pelo teste de Tukey. clorogênico, são influenciadas pela origem geográfica da variedade ou população em questão.

Segundo Montagnon et al. (1998), a variável lipídios apresenta alta herdabilidade, o que indica poucos genes envolvidos na expressão da característica, e possibilita uma eficiente seleção para o caráter desejado.

Os resultados obtidos neste trabalho demonstram variações significativas dos teores de lipídios totais nos grãos, em cada uma das seis variedades de C. canephora Pierre e entre elas; o conhecimento dessas variações é relevante no melhoramento dessa característica química da espécie, e também num possível incremento da qualidade de sua bebida.

\section{Agradecimentos}

À Capes, pela bolsa de doutorado outorgada ao primeiro autor; ao CNPq, pela bolsa concedida ao terceiro autor; à pesquisadora do Centro de Pesquisa e Desenvolvimento dos Recursos Genéticos e Vegetais do IAC/APTA, Cássia R.L. Carvalho, pelo auxílio na obtenção dos dados.

\section{Referências}

AGRIANUAL 2004: anuário da agricultura brasileira. São Paulo: FNP, 2004. p.185-202.

BANCO DE DESENVOLVIMENTO DO ESTADO DO ESPÍRITO SANTO. Diagnóstico da cafeicultura capixaba: o café robusta no Espírito Santo. Vitória: BANDES, 1987. 88p.

BANZATTO, D.A.; KRONKA, S.N. Experimentação agrícola. 3.ed. Jaboticabal: Funep, 1995. 247p.

BERTHAUD, J.; CHARRIER, A. Genetic resources of Coffea. In: CLARKE, R.J.; MACRAE, R. (Ed.). Coffee. London: Elsevier Applied Science, 1988. v.4, p.1-42.

CARVALHO, A. Distribuição geográfica e classificação botânica do gênero Coffea com referência especial à espécie arábica. Separata dos Boletins da Superintendência dos Serviços do Café, n.226230, 1946.

CONAGIN, C.H.T.M.; MENDES, A.J.T. Pesquisas citológicas e genéticas em três espécies de Coffea; auto-incompatibilidade em Coffea canephora Pierre Exfroehner. Bragantia, v.20, p.787-804, 1961.

DUSSERT, S.; LASHERMES, P.; ANTHONY, F.; MONTAGNON, C.; TROUSLOT, P.; COMBES, M.C.; BERTHAUD, J.; NOIROT, M.; HAMON, S. Le caféier, Coffea canephora. In: HAMON, P.; SEGUIN, M.; PERRIER, X.; GLASZMANN, J.C. Diversité génétique des plantes tropicales cultivées. Montpellier: CIRAD, 1999. p.175-194.

FAZUOLI, L.C. Genética e melhoramento do cafeeiro. In: RENA, A.B.; MALAVOLTA, E.; ROCHA, M.; YAMADA, T. Cultura do cafeeiro. Piracicaba: Potafos, 1986. p.87-113. 
FAZUOLI, L.C.; GALLO, P.B.; CERVELLINI, G.S.; BARROS, I. de; RAIJ, B. van. Café: Coffea arabica L. In: FAHL, J.I.; CAMARGO, M.B.P. de; PIZZINATTO, M.A.; BETTI, J.A.; MELO, A.M.T. de; DeMARIA, I.C.; FURLANI, A.M.C. Instruções agrícolas para as principais culturas econômicas. 6.ed. Campinas: Instituto Agronômico, 1998. p.59-63. (Boletim, 200).

FAZUOLI, L.C.; MALUF, M.P.; GUERREIRO FILHO, O.; MEDINA FILHO, H.P.; SILVAROLLA, M.B. Melhoramento clássico do cafeeiro relacionado com a biotecnologia moderna. In: SEMINÁRIO INTERNACIONAL SOBRE BIOTECNOLOGIA NA AGROINDÚSTRIA CAFEEIRA, 3., 1999, Londrina. Anais. Londrina: Elsevier, 1999. p.217-229.

FERRÃO, R.G.; FONSECA, A.F.A.; FERRÃO, M.A.G. Banco ativo de germoplasmas de Coffea canephora, variedade Conilon, no Estado do Espírito Santo. In: SIMPÓSIO DE PESQUISA DOS CAFÉS DO BRASIL, 1., Poços de Caldas, 2000. Anais. Brasília: Embrapa Café: Minasplan, 2000. p.405-408.

KY, C.L.; LOUARN, J.; DUSSERT, S.; GUYOT, B.; HAMON, S.; NOIROT, M. Caffeine, trigonelline, chlorogenic acids and sucrose diversity in wild Coffea arabica L. and C. canephora P. accessions. Food Chemistry, v.75, p.223-230, 2001.
MATIELO, N.N. Café conilon. Rio de Janeiro: MAA: SDR: Procafé: PNFC, 1998. 162p.

MAZZAFERA, P.; SOAVE, D.; ZULLO, M.A.T.; GUERREIRO FILHO, O. Oil content of green beans from some Coffee species. Bragantia, v.57, p.45-48, 1998.

MONTAGNON, C.; GUYOT, B.; CILAS, C.; LEROY, T. Genetic parameters of several biochemical compounds from green coffee, Coffea canephora. Plant Breeding, v.117, p.576-578, 1998.

PEZZOPANE, C.G.; MEDINA-FILHO, H.P.; BORDIGNON, R. Variabilidade genética do rendimento intrínseco de grãos em germoplasma de Coffea. Bragantia, v.63, p.39-54, 2004.

PIMENTA, C.J. Qualidade do café. Lavras: Ed. da Ufla, 2003. $304 p$.

STREULI, H. Der heutige stand der kaffeechemie. In: INTERNATIONAL SCIENTIFIC COLLOQUIUM ON GREEN AND ROASTED COFFEE CHEMISTRY, 6., 1973, Bogotá. Anais. Bogotá: Association Scientifique Internationale du Café, 1973. p.61-72.

Recebido em 22 de junho de 2004 e aprovado em 6 de maio de 2005 